\title{
Study on the Performance of Reactive Powder Concrete for Building Exterior Wall
}

\author{
Xin'e Yan ${ }^{1, a}$ \\ ${ }^{1}$ Xi'an Eurasia University, School of human settlements and civil engineering, shaan xi xi'an, China \\ ayanxine@126.com
}

Keywords: Reactive powder concrete; Flexural strength; Maximum fluidity; Workability

Abstract. Reactive powder concrete (RPC) is a cement-based material with excellent flexural strength. This study focuses on the flexural strength and maximum fluidity of RPC mixed with superplasticizer and steel fiber. In order to explore an optimized mix proportions of RPC, we make a research on the influences of superplasticizer content, steel fiber content, ratio of water to binder and aggregate particle size on the flexural strength and maximum fluidity of RPC in this work.

\section{Introduction}

With the development of economy and society, the recent construction trend in civil engineering is super-high strength, high durability and high toughness[1-2]. In the early 1990s a new building materials appeared in the building industry market by the French company BOUYGUES, called Reactive powder concrete (RPC) [3]. In this material, the particle size distribution was optimized by admixing silica fume or fine powders such as quartz sand to replace coarse aggregate, meanwhile, upperplasticizers was used in this building material to reduce water to cement ratio, and all of those improved packing density of RPC. Meanwhile, the short steel fiber has been added into this cement-based material, the flexural performance of RPC has been significantly improved [4].

Due to the excellent characteristics of reactive powder concrete, RPC was widely used in in military, nuclear power, ocean engineering and other fields [5-8]. In order to solve the problems of the exterior wall of building, such as leakage, cracking and shedding, it is necessary to find a kind of new building material which has good impermeability, bending resistance and durability [9-12]. In this work, RPC has been prepared and the effects of its composition on performance of RPC have been researched.

\section{Experiment}

A comprehensive experimental program has been carried out according to following details. The experimental variables include superplasticizer incorporation ratio $(1 \%, 1.25 \%, 1.5 \%, 1.75 \%$ and $2 \%)$, water/binder ratio $(0.18,0.19,0.20,0.21$ and 0.2$)$, steel fiber content $(1 \%, 2 \%, 3 \%, 4 \%$ and $5 \%)$ and aggregate size gradation $(0: 5,1: 4,2: 3,3: 2,4: 1$ and 5:0).

An ordinary type Portland cement P.O 42.5 was used in this study. The chemical composition of cementitious material was given in Table 1, and some physical and mechanical properties of the Portland cement are also shown in Table 2.

Table 1 Chemical composition of cementious material

\begin{tabular}{llllllll}
\hline $\begin{array}{l}\text { Chemical } \\
\text { composition }\end{array}$ & $\mathrm{SiO}_{2}$ & $\mathrm{Al}_{2} \mathrm{O}_{3}$ & $\mathrm{CaO}$ & $\mathrm{MgO}$ & $\mathrm{SO}_{3}$ & $\mathrm{Fe}_{2} \mathrm{O}_{3}$ & L.O.I. \\
\hline Content $(\%)$ & 22.34 & 4.37 & 61.89 & 4.46 & 2.28 & 2.04 & 2.62 \\
\hline
\end{tabular}

Silica fume (SF) was used as the secondary binder. The undensified amorphous SF containing above $95 \% \mathrm{SiO}_{2}$ was provided, and the specific surface area was $15300 \mathrm{~m} 2 / \mathrm{kg}$. The physical and chemical properties of the SF were provided in Table 3. 
Table 2 Physical and mechanical properties of the Portland cement

\begin{tabular}{|c|c|c|c|c|c|c|}
\hline \multirow[t]{2}{*}{ fineness/\% } & \multicolumn{2}{|c|}{ setting time / $\min$} & \multicolumn{2}{|c|}{$\begin{array}{l}\text { Flexural } \\
\text { Strength/ MPa }\end{array}$} & \multicolumn{2}{|c|}{$\begin{array}{l}\text { compressive strength/ } \\
\mathrm{MPa}\end{array}$} \\
\hline & Initial & Final & $3 d$ & $28 \mathrm{~d}$ & $3 d$ & $28 d$ \\
\hline 5.8 & 160 & 350 & 5.22 & 8.68 & 28.4 & 49.8 \\
\hline
\end{tabular}

Usually, the water/cement ratio was usually replaced by the water/binder ratio (W/B) to adjust the property of RPC. In order to adjust the rheological behavior of RPC, a polycarboxilate type superplasticizer was utilized with different contents.

According to the particle size, quartz sand is divided into two grade, i.e. coarse sand (particle size $0.250-2 \mathrm{~mm})$ and fine sand $(0-0.25 \mathrm{~mm})$. Finally, steel fiber (length $12 \mathrm{~mm}$, diameter $0.35 \mathrm{~mm}$ ) was used to enhance the toughness of RPC.

Table 3 Chemical composition of SF (\%)

\begin{tabular}{ccccccccc}
\hline $\mathrm{SiO}_{2}$ & $\mathrm{C}$ & $\mathrm{Al}_{2} \mathrm{O}_{3}$ & $\mathrm{CaO}$ & $\mathrm{MgO}$ & $\mathrm{SO}_{3}$ & $\mathrm{Fe}_{2} \mathrm{O}_{3}$ & $\mathrm{Na}_{2} \mathrm{O}$ & $\mathrm{K}_{2} \mathrm{O}$ \\
\hline$>95$ & 0.45 & 0.74 & 1.12 & 0.75 & 0.08 & 0.45 & 0.16 & 0.23 \\
\hline
\end{tabular}

The raw materials have been mixed by following certain requirements. Firstly, the pre-weighed dry powders (cement, silica fume and quartz sand) were poured into the concrete mixer and stirred for $1 \mathrm{~min}$. And, the pre-weighed superplasticizer and water were poured into mixer and stirred for about $5 \mathrm{~min}$. Lastly, steel fibers were thrown into mixer and stirred for about $2 \mathrm{~min}$. Then, the mixture was injected into the mold and stored for $24 \mathrm{~h}$ at room temperature of about $20{ }^{\circ} \mathrm{C}$. After demolded, the specimens were move into standard curing room and cure for 28 days.

The flexural strength was evaluated in accordance with Chinese standard GB/T 50081-2002. For each measurement, a set of three specimens $150 \times 150 \times 550 \mathrm{~mm} 3$ was used. The tests were performed at the age of 28 days. The maximum fluidity was evaluated in accordance with Chinese standard GB/T 8077-2000.

\section{Results and discussion}

\section{Effect of content of superplasticizer}

Superplasticizer is a kind of polymer surfactant, which has strong solid liquid interface activity. In the cement dispersing system, it can be adsorbed on the surface of the cement particles, and reduce the surface energy of the cement particles to form negative electric field. In the same electrostatic repulsion, the cement particles have been dispersed and the water which enclosed the cement particles can be released, so the fluidity of cement paste has been greatly improved. Changing the content of superplasticizer was found to influence RPC flexural strength and maximum fluidity by using a constant total water to cement ratio (Fig. 1). The results show that the maximum fluidity of cement paste increase with the increase content of superplasticizer. At the end of the flow test, flow of RPC ranged from $108 \mathrm{~mm}$ to $210 \mathrm{~mm}$. But the flexural strength of RPC shows a opposite tendency by increasing the content of superplasticizer, and the flexural strength of RPC is only $15.8 \mathrm{MPa}$ when the content of superplasticizer is $4 \%$. In order to take into account the flexural strength and workability of $\mathrm{RPC}$, the content of superplasticizer has been determined to be $1.5 \%$. 


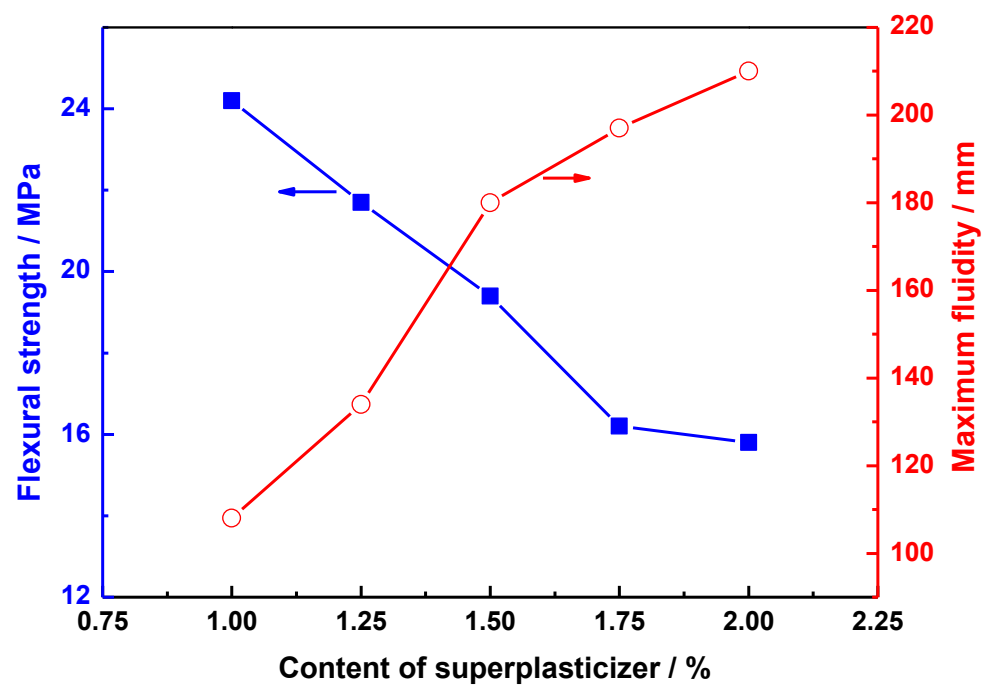

Fig.1. The effect of superplasticizer content on flexural fluidity and maximum fluidity of RPC

\section{Effect of water to binder ratio}

Water to binder ratio reflects the amount of water used in the stirring process of RPC. The flexural strength and the maximum fluidity of RPC with different water to binder ratio have been shown in Fig.2. This is quite a good understanding that the lower the water to binder ratio of RPC, the lower is its maximum fluidity, so the lower is its workability. From Fig.2, higher flexural strength has been observed at lower water to binder ratio of RPC, and the flexural strength of RPC decreases linearly with the increase of water to binder ratio. Similarly, in order to maintain good workabilty and high flexural strength of RPC, the water to binder ratio of RPC has been determined to be 0.2 .

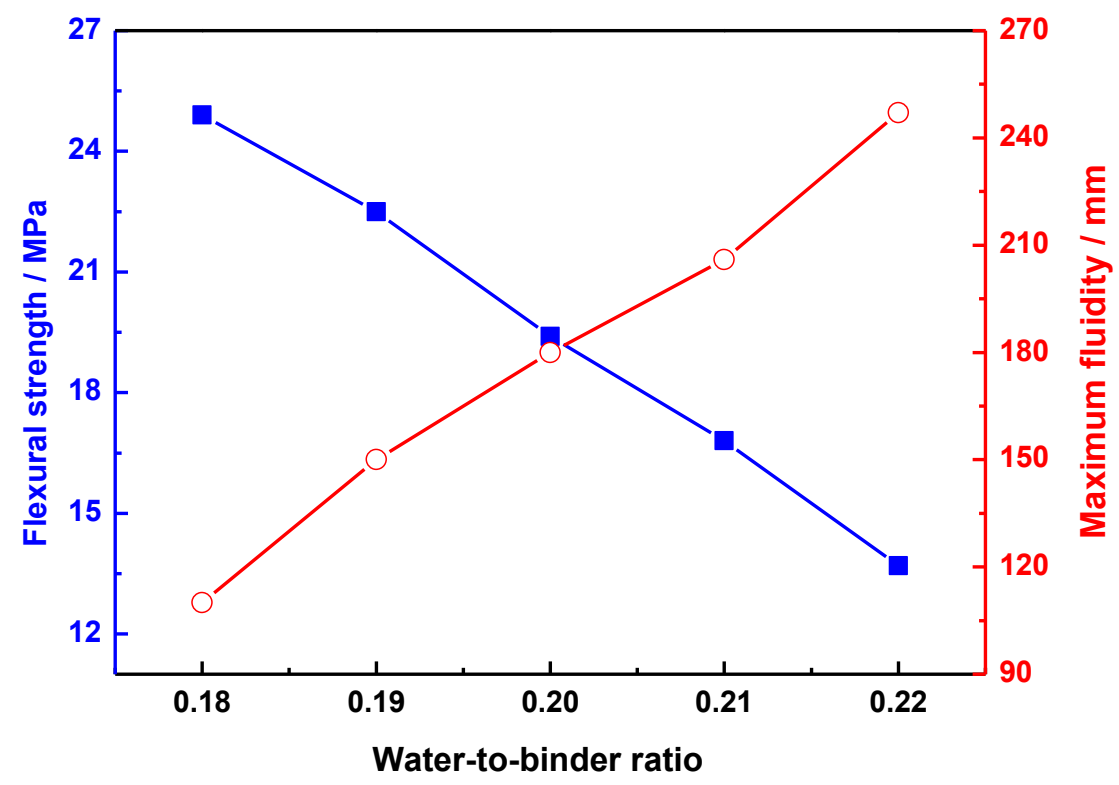

Fig.2. The effect of ratio of water to binder on flexural fluidity and maximum fluidity of RPC

\section{Effect of different content of steel fiber}

Steel fiber has been utilized as the toughening material to increase the flexural strength in RPC. When the content of steel fiber reaches an appropriate value, the flexural strength of concrete reaches a maximum value; hence, the content of $4 \%$ seems to be suitable as also observed in Fig. 3 . 
Fig. 3 also depicts the relation between maximum fluidity and steel fiber. In the experimental test range, the maximum fluidity of RPC decrease with an increase in steel fiber content. Considering the flexural strength and workability of RPC, the content of steel fiber in RPC is $4 \%$ that seems more appropriate.

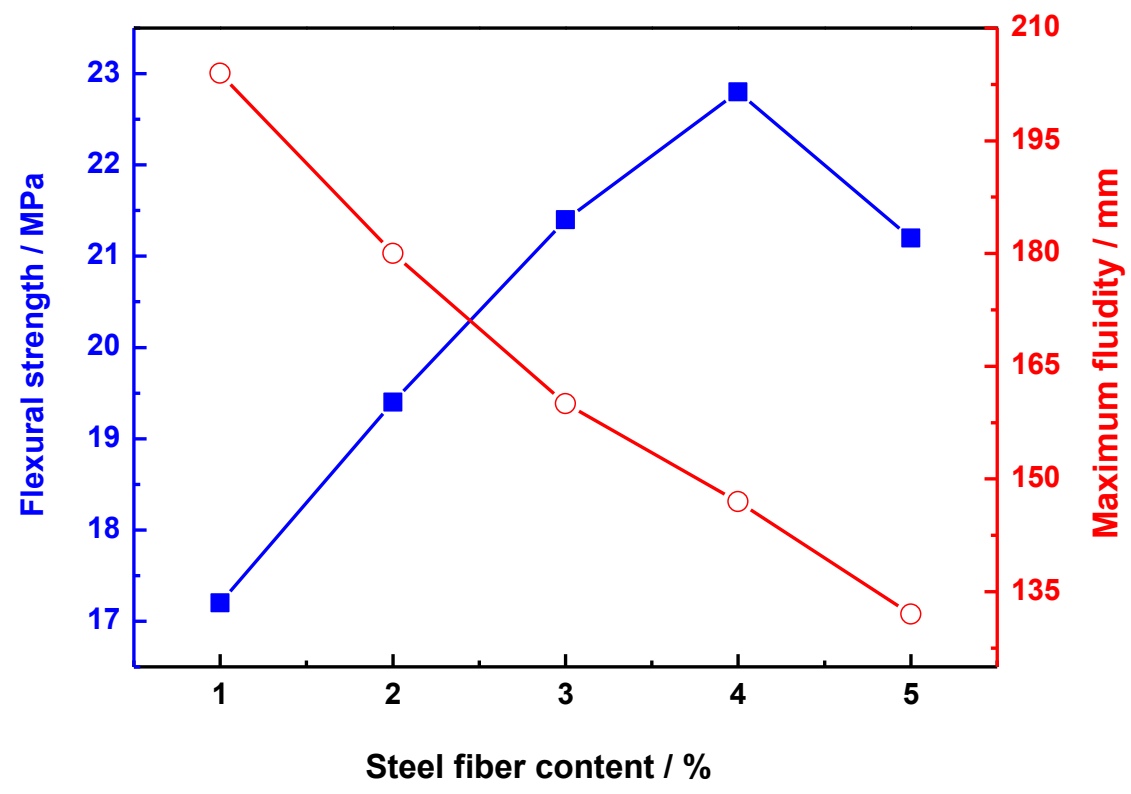

Fig.3. The effect of steel fiber content on flexural fluidity and maximum fluidity of RPC

\section{Effect of aggregate particle size}

The superior performance of RPC is derived from the optimization of particle size grading of the aggregate. Reasonable aggregate size distribution can effectively reduce the pore structure of RPC and increase its compactness, so as to improve the performance of RPC. The relationship between the flexural strength of RPC versus the ratio of fine sand to coarse sand has been shown in Fig.4. It may be seen from Fig. 4 that the flexural strength of RPC reached a maximum value while the ratio of fine sand to coarse sand is 1:4. It is clear from the Fig.4 that the maximum fluidity of RPC decline with the increasing the content of fine sand. Based on the above discussion, it is observed that RPC with the ratio of fine sand to coarse sand being 1:4 can exhibit good performance.

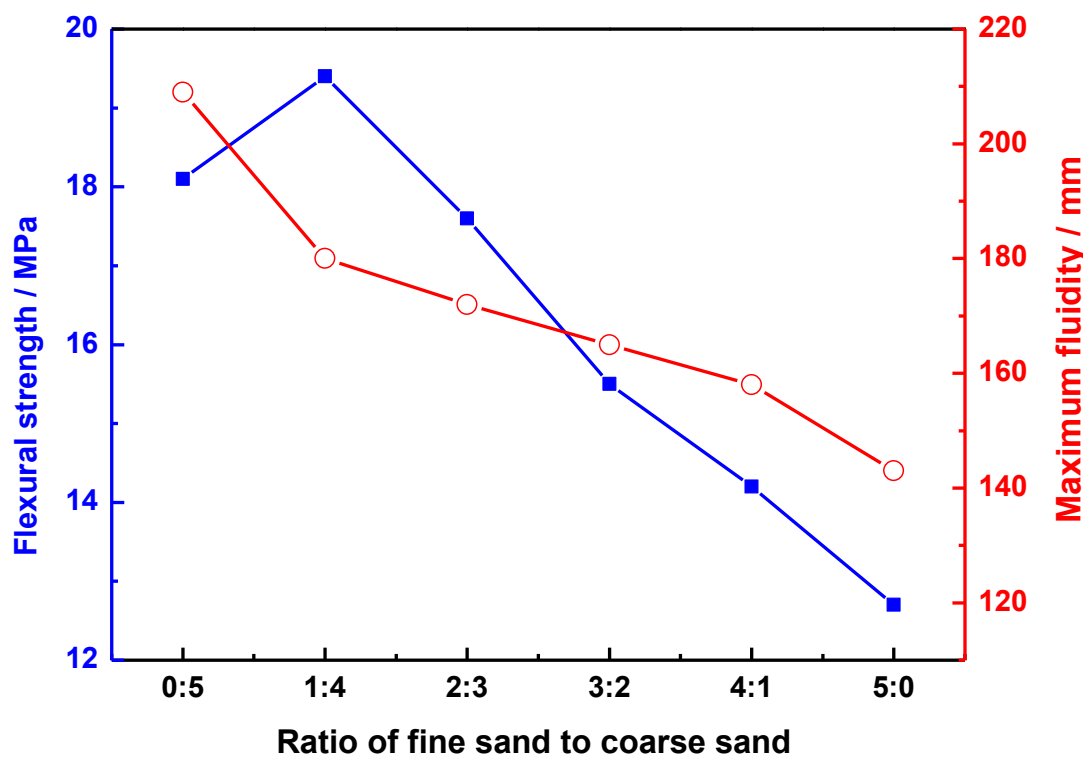

Fig.4. The effect of ratio of fine sand to coarse sand on flexural fluidity and maximum fluidity of RPC 


\section{Conclusions}

This paper has investigated the flexural strength and maximum fluidity of RPC. Different content of superplasticizer and ratio of water to binder were experimented. It was found that RPC generally exhibited relatively high flexural strength when the water consumption was reduced, but the maximum fluidity of RPC showed an opposite trend. It was also found that moderate steel fiber content and optimized aggregate particle size grading can increase the flexural strength. According to test results, the content of superplasticizer is $1.5 \%$, and the ratio of water to binder is 0.2 , and the content of steel fiber is $4 \%$, and the quality ratio of fine sand to coarse sand is $1: 4$, so we can make a conclution that RPC has good flexural strength and workability which can be used as building exterior wall materials.

\section{Acknowledgment}

This research was financially supported by the special program of Shaanxi provincial education department (No.JK2084).

\section{References}

[1] S C.J, Wu Z.M, Xiao J.F, Wang D.H, Huang Z.Y, Fang Z. Construction and Building Materials, 101 (2015) p741-751

[2] Muhd N.M.S, Hamidah M.S, Fadzil A.M. Construction and Building Materials, 133(2017) p 91-97

[3] Richard P, Cheyrezy M. Cement \& Concrete Research, 25(1995) p1501-1511

[4] Bae B, Choi H.K, Choi C.S. Construction and Building Materials, 112(2016), p825-835

[5] Greg B. Civil Engineer Magazine, 71(2001), p14-18

[6] Bierwagen D, hawash A A. Proceeding of the 2005 Mid-Continebt transportation symposium, Iowa, 2005, 1-1

[7] O’Neil, Edward F, Dowd, William M. Proceedings of Materials Engineering Conference, 1996, ASCE, 1320-1329

[8] Lee M.G, Wang Y.C, Chiu C.T. Construction and Building Materials, 21 (2007), p182 - 189

[9] Mehmet C. Construction and Building Materials, 70 (2014), p508-513

[10] Ji T, Chen C.Y, Zhuang Y.Z. Construction and Building Materials, 28 (2012), p45-49

[11] Cwirzen A, Penttala V, Vornanen C. Cement and Concrete Research, 38 (2008), p1217-1226

[12] Isamu Y, Yusuke K, Yasuo W, Yail J.K. Construction and Building Materials, 111(2016), p22-29 